\title{
The genome sequence of Schizosaccharomyces pombe
}

\author{
V. Wood', R. Gwilliam', M.-A. Rajandream', M. Lyne', R. Lyne', A. Stewart', J. Sgouros², N. Peat ${ }^{3}$, J. Hayles ${ }^{3}$, S. Baker', D. Basham', \\ S. Bowman', K. Brooks', D. Brown', S. Brown', T. Chillingworth', C. Churcher', M. Collins', R. Connor', A. Cronin', P. Davis', T. Feltwell', \\ A. Fraser', S. Gentles', A. Goble', N. Hamlin', D. Harris', J. Hidalgo', G. Hodgson', S. Holroyd', T. Hornsby', S. Howarth', E. J. Huckle', \\ S. Hunt', K. Jagels', K. James', L. Jones', M. Jones', S. Leather', S. McDonald', J. McLean', P. Mooney', S. Moule', K. Mungall', \\ L. Murphy', D. Niblett', C. Odell', K. Oliver', S. O'Neil', D. Pearson', M. A. Quail', E. Rabbinowitsch', K. Rutherford', S. Rutter', \\ D. Saunders', K. Seeger', S. Sharp', J. Skelton', M. Simmonds', R. Squares', S. Squares', K. Stevens', K. Taylor', R. G. Taylor', \\ A. Tivey', S. Walsh', T. Warren', S. Whitehead', J. Woodward', G. Volckaert', R. Aert', J. Robben' ${ }^{4}$, B. Grymonprez ${ }^{4}$, I. Weltjens ${ }^{4}$, \\ E. Vanstreels ${ }^{4}$, M. Rieger ${ }^{5}$, M. Schäfer ${ }^{5}$, S. Müller-Auer ${ }^{5}$, C. Gabel ${ }^{5}$, M. Fuchs ${ }^{5}$, C. Fritzc ${ }^{6}$, E. Holzer ${ }^{6}$, D. Moestl ${ }^{6}$, H. Hilbert ${ }^{6}$, K. Borzym ${ }^{7}$, \\ I. Langer ${ }^{7}$, A. Beck ${ }^{7}$, H. Lehrach ${ }^{7}$, R. Reinhardt' ${ }^{7}$, T. M. Pohl' ${ }^{8}$, P. Eger ${ }^{8}$, W. Zimmermann ${ }^{9}$, H. Wedler ${ }^{9}$, R. Wambutt ${ }^{9}$, B. Purnelle ${ }^{10}$, \\ A. Goffeau ${ }^{10}$, E. Gadieu ${ }^{11}$, S. Dréano ${ }^{11}$, S. Gloux ${ }^{11}$, V. Lelaure ${ }^{11}$, S. Mottier ${ }^{11}$, F. Galibert ${ }^{11}$, S. J. Aves ${ }^{12}$, Z. Xiang ${ }^{12}$, C. Hunt ${ }^{12}$, K. Moore ${ }^{12}$, \\ S. M. Hurst ${ }^{12}$, M. Lucas ${ }^{13}$, M. Rochet ${ }^{13}$, C. Gaillardin ${ }^{13}$, V. A. Tallada ${ }^{14,15}$, A. Garzon ${ }^{14,15}$, G. Thode ${ }^{14}$, R. R. Daga ${ }^{14,15}$, L. Gruzado ${ }^{14}$, \\ J. Jimenez ${ }^{14,15}$, M. Sánchez ${ }^{16}$, F. del Rey ${ }^{16}$, J. Benito ${ }^{16}$, A. Dominguez ${ }^{16}$, J. L. Revuelta ${ }^{16}$, S. Moreno ${ }^{16}$, J. Armstrong ${ }^{17}$, S. L. Forsburg ${ }^{18}$, \\ L. Cerrutti' ${ }^{1}$, T. Lowe ${ }^{19}$, W. R. McCombie ${ }^{20}$, I. Paulsen ${ }^{21}$, J. Potashkin ${ }^{22}$, G. V. Shpakovski ${ }^{23}$, D. Ussery ${ }^{24}$, B. G. Barrell ${ }^{1}$ \& P. Nurse ${ }^{3}$
}

We have sequenced and annotated the genome of fission yeast (Schizosaccharomyces pombe), which contains the smallest number of protein-coding genes yet recorded for a eukaryote: 4,824. The centromeres are between 35 and 110 kilobases (kb) and contain related repeats including a highly conserved 1.8-kb element. Regions upstream of genes are longer than in budding yeast (Saccharomyces cerevisiae), possibly reflecting more-extended control regions. Some $43 \%$ of the genes contain introns, of which there are 4,730. Fifty genes have significant similarity with human disease genes; half of these are cancer related. We identify highly conserved genes important for eukaryotic cell organization including those required for the cytoskeleton, compartmentation, cell-cycle control, proteolysis, protein phosphorylation and RNA splicing. These genes may have originated with the appearance of eukaryotic life. Few similarly conserved genes that are important for multicellular organization were identified, suggesting that the transition from prokaryotes to eukaryotes required more new genes than did the transition from unicellular to multicellular organization.

We report here the completion of the fully annotated genome sequence of the simple eukaryote Schizosaccharomyces pombe, a fission yeast. It becomes the sixth eukaryotic genome to be sequenced, following Saccharomyces cerevisiae ${ }^{1}$, Caenorhabditis elegans $^{2}$, Drosophila melanogaster ${ }^{3}$, Arabidopsis thaliana ${ }^{4}$ and Homo sapiens ${ }^{5,6}$. The entire sequence of the unique regions of the three chromosomes is complete, with gaps in the centromeric regions of about $40 \mathrm{~kb}$, and about $260 \mathrm{~kb}$ in the telomeric regions. The completion of this sequence, the availability of sophisticated research methodologies, and the expanding community working on $S$. pombe, will accelerate the use of $S$. pombe for functional and comparative studies of eukaryotic cell processes.

Schizosaccharomyces pombe is a single-celled free living archiascomycete fungus sharing many features with cells of more complicated eukaryotes. From gene sequence comparisons and phylogenetic analyses, it has been suggested that fission yeast diverged from budding yeast around 330-420 million years (Myr) ago, and from Metazoa and plants around 1,000-1,200 $\mathrm{Myr} \mathrm{ago}^{7}$, although a more recent estimate has put these times at 1,144 and $1,600 \mathrm{Myr}$, respectively ${ }^{8}$. Some gene sequences are as equally diverged between the two yeasts as they are from their human homologues, probably reflecting a more rapid evolution within fungal lineages than in the Metazoa. S. pombe was first described in the 1890 s and has been extensively studied since the $1950 \mathrm{~s}^{9,10}$, resulting in the characterization of around 1,200 genes (http:// www.genedb.org/pombe). The ease with which it can be genetically manipulated is second only to $S$. cerevisiae among eukaryotes and it has served as an excellent model organism for the study of cell-cycle control, mitosis and meiosis ${ }^{11}$, DNA repair and recombination ${ }^{12}$, and the checkpoint controls important for genome stability ${ }^{13}$.

The 13.8-Mb genome of $S$. pombe is distributed between chromosomes I (5.7 Mb), II (4.6 Mb) and III $(3.5 \mathrm{Mb})^{14}$, together with a $20-\mathrm{kb}$ mitochondrial genome ${ }^{15}$. Tandem arrays of $100-120$ repeats of a 10.4-kb fragment containing the 5.8S, $18 \mathrm{~S}$ and $25 \mathrm{~S}$ ribosomal RNA genes account for around $1.1 \mathrm{Mb}^{16}$. The three centromeres are 35,65 and $110 \mathrm{~kb}$ long for chromosomes I, II and III, respectively, totalling $0.2 \mathrm{Mb}$. This leaves about $12.5 \mathrm{Mb}$ of unique sequence, similar in size to that of $S$. cerevisiae, and substantially smaller than those of the three other sequenced model eukaryotes, C. elegans (97 Mb), Arabidopsis (125 Mb) and Drosophila (137 Mb). All of the
${ }^{1}$ The Wellcome Trust Sanger Institute, The Wellcome Trust Genome Campus, Hinxton, Cambridge CB10 1SA, UK. ${ }^{2}$ Cancer Research UK London Research Institute, Computational Genome Analysis Laboratory, 44 Lincoln's Inn Fields, London WC2A 3PX, UK. ${ }^{3}$ Cancer Research UK London Research Institute, Cell Cycle Laboratory, 44 Lincoln's Inn Fields, London, WC2A 3PX, UK. ${ }^{4}$ Katholieke Universiteit Leuven, Faculty of Agricultural and Applied Biological Sciences, Laboratory of Gene Technology, Kardinaal Mercierlaan 92 Blok F, B-3001 Leuven, Belgium. ${ }^{5}$ Genotype GmbH, Molecular Biology and Biotech Research, Angelhofweg 39, D-69259 Wilhelmsfeld, Germany. ${ }^{6}$ QIAGEN GmbH, Max Volmer Str. 4, D-40724 Hilden, Germany. ${ }^{7}$ Max-Planck-Institut für molekulare Genetik, Ihnestrasse 73 , D-14195 Berlin, Germany. ${ }^{8}$ GATC Biotech AG, Jakob-Stadler-Platz 7, D-78467 Konstanz, Germany. ${ }^{9}$ AGOWA GmbH, Glienicker Weg 185, D-12489 Berlin, Germany. ${ }^{10}$ Université de Louvain, Unite de Biochimie Physiologique, Place Croix du Sud 2-20, B1348 Louvain-la-Neuve, Belgium. ${ }^{11}$ UMR 6061 CNRS Genetique et developpement, Faculté de Médecine, 2 avenue du Professeur Léon Bernard, F-35043 Rennes Cedex, France. ${ }^{12}$ University of Exeter, School of Biological Sciences, Washington Singer Laboratories, Perry Road, Exeter EX4 4QG, UK. ${ }^{13}$ Génétique Moléculaire et Cellulaire, CNRS URA1925 INRA
UMR216, Institut National Agronomique Paris-Grignon, 78850 Thiverval Grignon, France. ${ }^{14}$ Departamento de Genetica, Facultad de Ciencias, Universidad de Malaga, Spain. ${ }^{15}$ Laboratorio Andaluz de Biologia, Universidad Pablo de Olavide, Sevilla, Spain. ${ }^{16}$ Instituto de Microbiología y Bioquímica, Departamento de Microbiología y Genética, CSIC/Universidad de Salamanca, Edificio Departamental, Campus Miguel de Unamuno, 37007 Salamanca, Spain. ${ }^{17}$ University of Sussex, Falmer, Brighton BN1 9QG, UK. ${ }^{18}$ Molecular \& Cell Biology Laboratory, Salk Institute for Biological Studies, 10010 North Torrey Pines Road, La Jolla, California 92037-1099, USA. ${ }^{19}$ Stanford University, Stanford University School of Medicine, Department of Genetics, CCSR Room 2255b, 269 Campus Drive, Stanford, California 94305, USA. ${ }^{20}$ Cold Spring Harbor Laboratory, PO Box 100, 1 Bungtown Road, Cold Spring Harbor, New York 11724, USA. ${ }^{21}$ TIGR, 9712 Medical Center Drive, Rockville, Maryland 20850, USA. ${ }^{22}$ The Chicago Medical School, 3333 Green Bay Road, North Chicago, Illinois 60064, USA. ${ }^{23}$ Shemyakin-Ovchinnikov Institute of Bioorganic Chemistry, Russian Academy of Sciences, Ul. Miklukho-Maklaya 16/10, 117997 Moscow, Russia. ${ }^{24}$ Center for Biological Sequence Analysis, BioCentrum-DTU, The Technical University of Denmark, Building 208, DK-2800 Kgs. Lyngby, Denmark. 
unique sequence and most of the three centromeres of the Urs Leupold $972 \mathrm{~h}^{-}$strain $^{9}$ have been sequenced by the Wellcome Trust Sanger Institute and the 13 other laboratories that make up the $S$. pombe European Sequencing Consortium (EUPOM), together with $100 \mathrm{~kb}$ of sequence generated by the Cold Spring Harbor Laboratory (GenBank accession numbers AL355920, AL355921, AL391034 and AL391016). Here, we present and discuss the genome sequence and composition, and carry out an initial overview of gene function, making comparisons with other eukaryotic organisms, particularly S. cerevisiae.

\section{Mapping, sequencing and sequence analysis}

A clone map was generated by the integration of the two preexisting maps ${ }^{17,18}$. End sequencing and restriction digestion of cosmids were used to construct a minimal tile path for sequencing. Problems with the earlier maps included the existence of chimaeric clones, mismapped cosmids, bacterial insertion elements and unfilled gaps. Small gaps were covered using a long-range polymerase chain reaction (PCR) strategy, plasmid libraries, and a bacterial artificial chromosome (BAC) library provided clones for gap closure across regions not represented in the cosmid libraries. The final $12.5-\mathrm{Mb}$ sequence of the $S$. pombe genome is a composite of 452 cosmids, 22 plasmids, 15 BAC clones and 13 PCR products.

Most sequencing was performed using random sequencing of sub-cloned DNA followed by directed sequencing ${ }^{19}$. DNA from clones was shattered (usually by sonication) and fragments of 1.4$2 \mathrm{~kb}$ were cloned, typically, into M13 or pUC18. Random subclones were sequenced with dye-terminator chemistry and analysed on automated sequencers. Most laboratories used Phred software for sequence base calling and Phrap or Gap4 for contig assembly ${ }^{20}$. Gaps and low-quality regions of the sequence were resolved using primer walking, PCR and re-sequencing clones, under conditions that gave increased read lengths. Some laboratories also used direct blotting procedures, classical radioactive sequencing and nested deletions. All sequences were finished to a high degree of accuracy, with at least two high-quality reads on each strand, or, if this could not be accomplished, an additional read on the same strand using an alternative chemistry. The depth of coverage was on average eightfold. Sequences were collected centrally at the Wellcome Trust Sanger Institute, where the quality was examined by comparison of overlapping regions and by checking for frameshifts in coding regions. The sequencing error rate was less than 1 in 180,000 base pairs (bp), calculated from the number of single-base differences observed in overlapping sequences from different sources. All identified sequencing errors have been resolved with the exception of four single-base differences found in homopolymeric tracts located outside coding regions, possibly generated by slippage during DNA replication.

Gene prediction was carried out with GENEFINDER (P. Green and L. Hillier, unpublished software) trained on experimentally confirmed $S$. pombe genes to recognize intronic and coding regions. Additional information was provided using a Hidden Markov Model trained on intron sequences using HMMER (http:// hmmer. wustl.edu/hmmer-html/). Searches were performed against public databases (SWISS-PROT and TrEMBL ${ }^{21}, \mathrm{EMBL}^{22}$ and Pfam $^{23}$ ), using BLAST ${ }^{24}$, MSPcrunch ${ }^{25}$, FASTA ${ }^{26}$ and Genewise ${ }^{27}$. The predictions were refined manually within the Artemis analysis and annotation tool ${ }^{28}$ using protein homology and expressed sequence tag (EST) data ${ }^{29}$. Because most $S$. pombe genes have a prospective homologue in other organisms, putative functions were assigned on the basis of similarities to known genes, using the SWISS-PROT ${ }^{21}, \mathrm{Pfam}^{23}$, Proteome ${ }^{30}, \mathrm{SGD}^{31}$ and MIPS databases ${ }^{32}$. Identification of transfer RNA was carried out using the tRNA scanSE software ${ }^{33}$.

Prediction of genes in fission yeast is a problem of intermediate complexity. It is more difficult than the analysis of tightly packed genomes that have little or no splicing, as found in prokaryotes and budding yeast, but less difficult than gene prediction in multicellular eukaryotes, which have lower gene density, high levels of splicing, and long introns. There are 4,730 confirmed and predicted introns in $S$. pombe, many more than the 272 now predicted for $S$. cerevisiae. $S$. pombe introns average only 81 nucleotides in length and so are shorter and easier to predict than those found in Metazoa and plants. Of the 4,730 introns in S. pombe, 638 have been confirmed experimentally by messenger RNA and EST data ${ }^{29}$, and many more by homology.

\section{Genome content}

We predicted a maximum of 4,940 protein coding genes (including 11 mitochondrial genes) and 33 pseudogenes. The three gene maps showing these predictions can be viewed at $\mathrm{ftp}: / / \mathrm{ftp}$.sanger.ac.uk/ pub/yeast/pombe/GeneMaps/. All open reading frames (ORFs) over 100 amino acids with an initiator methionine and not overlapping with other known genes are included in this set. Also included are 147 confirmed or predicted protein-coding sequences of 25-99 amino acids. Any remaining undiscovered genes are likely to have either a highly spliced structure with small exons, or to be smaller than 100 amino acids. There are a further 116 questionable proteins considered less likely to be coding because they are small, have no detectable homologies, and display low coding potential. Removal of these questionable genes reduces the predicted gene complement from 4,940 to 4,824 .

Even our upper estimate of 4,940 genes for $S$. pombe is substantially less than the 5,570-5,651 genes predicted for S. cerevisiae ${ }^{34,35}$, the 6,752 genes predicted for Mesorhizobium loti, the largest published prokaryote genome sequence to date ${ }^{36}$, and the 7,825 genes estimated in the $8.67-\mathrm{Mb}$ genome of the prokaryote Streptomyces coelicolor (J. Parkhill and S. Bentley, personal communication). We conclude that a free-living eukaryotic cell can be constructed with fewer than 5,000 genes, and that the distinction between eukaryotic and prokaryotic cell organization is not determined simply by total number of genes but depends on the types of genes present and how they interact with each other and the environment. Comparing the genome content of species at different levels of organization, it seems that fewer than 500 genes are sufficient to generate a parasitic prokaryotic cell such as Mycoplasma genitalium ${ }^{37}$, about 1,500 genes for a free-living prokaryotic cell such as Aquifex aeolicus ${ }^{38}, 5,000$ genes for a free-living eukaryotic cell (S. cerevisiae and S. pombe; ref. 39 and this paper), and around 15,000 genes for multicellular eukaryotic organisms such as Drosophila and C. elegans ${ }^{2,3}$, whereas 30,000-40,000 genes gives rise to human consciousness ${ }^{5,6}$.

Gene density is similar for chromosomes I and II, with one gene every 2,483 and 2,457 bp respectively, but is less dense for chromosome III, at one gene every $2,790 \mathrm{bp}$. This is not due to differences in the average length of the genes, which are similar (1,407-1,446 bp) for all three chromosomes (Table 1). Protein-coding genes are absent from the centromeres, although tRNA genes are found in these regions. Gene density is also lower at the telomeres. The gene density for the complete genome is one gene every 2,528 bp, compared with one gene every $2,088 \mathrm{bp}$ for $S$. cerevisiae. The protein-coding sequence is predicted to occupy $60.2 \%(57 \%$ excluding introns) of the sequenced portion of the $S$. pombe genome, compared with $71 \%$ in S. cerevisiae (70.5\% excluding introns). The overall guanine and cytosine (GC) content is $36.0 \%$, compared with $38.3 \%$ in $S$. cerevisiae, and for the protein-coding portion is identical in the two yeasts at $39.6 \%$.

We have identified a total of 174 tRNAs, 45 of which have introns; all the tRNA families needed to decode all codons are present. The spliceosomal RNAs (U1-U6) are found together with 16 small nuclear RNA genes (snRNAs) and 33 small nucleolar RNAs (snoRNAs). These are dispersed mostly as singletons throughout the genome. The 5.8S, $18 \mathrm{~S}$ and $26 \mathrm{~S}$ ribosomal RNA genes are grouped 


\begin{tabular}{|c|c|c|c|c|c|c|c|c|c|c|}
\hline & Length (bp) & No. of genes & No. of Tf2s & $\begin{array}{c}\text { No. of } \\
\text { pseudo Tf2s }\end{array}$ & No. of wtfs & $\begin{array}{c}\text { No. of } \\
\text { lone LTRs }\end{array}$ & $\begin{array}{c}\text { No. of } \\
\text { pseudogenes }\end{array}$ & $\begin{array}{l}\text { Mean gene } \\
\text { length }(b p)^{*}\end{array}$ & Gene density† & Coding (\%) \\
\hline Chromosome 1 & $5,598,923$ & 2,255 & 8 & 0 & 1 & 77 & 17 & 1,446 & 2,483 & 58.6 \\
\hline Chromosome 2 & $4,397,795$ & 1,790 & 2 & 1 & 1 & 53 & 9 & 1,411 & 2,457 & 57.5 \\
\hline Chromosome 3 & $2,465,919$ & 884 & 1 & 2 & 23 & 50 & 7 & 1,407 & 2,790 & 54.5 \\
\hline Whole genome & $12,462,637$ & 4,929 & 11 & 3 & 25 & 180 & 33 & 1,426 & 2,528 & 57.5 \\
\hline
\end{tabular}

${ }^{*}$ Mean gene length excluding introns.

† Gene density, given as average bp per gene.

together as 100-120 tandem repeats in two arrays on chromosome $\mathrm{III}^{40}$, but the thirty $5 \mathrm{~S}$ ribosomal RNA genes are distributed throughout the genome $\mathrm{e}^{41}$, providing opportunities for unequal crossing over when they are in tandem orientation and close proximity. This can lead to local duplications and deletions of genes located between the 5S RNA genes ${ }^{42}$. There are 11 intact transposable elements (Tf2 type) (Table 1), accounting for $0.35 \%$ of the genome. This is significantly less than the $2.4 \%$ (59 elements) found in S. cerevisiae ${ }^{43}$ and the $10 \%$ found in Arabidopsis ${ }^{4}$, and is also likely to be much less than the numbers in Drosophila and humans ${ }^{44,45}$. There are $25 \mathrm{wtf}$ elements ('with tf1- or tf2-type' long terminal repeats, LTRs), which appear to be spliced membrane proteins of $S$. pombe. These elements are often flanked by LTRs, and so may have been duplicated by retrotransposition. There are also 180 solo LTRs, marking former transposition events, compared with 268 found in S. cerevisiae. The density of transposable element remnants on chromosome III of $S$. pombe is twice that of chromosomes I and II (Table 1).

We examined 73 genetically and physically mapped genes from the three gene maps; comparison of these maps shows that they are essentially co-linear and that the level of recombination is similar throughout the three chromosomes. More detailed comparisons of the genetic and physical maps may reveal subtle variations in recombination around centromeres, telomeres, the mating-type locus, and sites of meiotic DNA double-strand breaks. Several inconsistencies in the genetic maps were identified, including the reversal of a chromosome II fragment near the telomere between trp1 and spo4 (ref. 46), the relocation of cut1 and wee1 from the telomere region to the centromere region of chromosome III, and changes in position of lys1 and top1.

\section{Centromere structures}

The outline structure of the centromeres has previously been deduced by Southern blotting and by sequencing about $14 \%$ of the centromere repeat regions ${ }^{47-49}$. Here, we sequenced most $(81 \%)$ of the three centromeres; this has allowed schematic maps of the centromeres to be verified (Fig. 1). The nomenclature used follows that of the Yanagida group ${ }^{50,51}$; however, other designations of the centromere elements have been used ${ }^{52}$. The most complete sequence is for centromere 1 , which is the shortest at $35 \mathrm{~kb}$ and is missing only one $2.5-\mathrm{kb}$ fragment. This centromere consists of a central core (cnt1) of $4.1 \mathrm{~kb}$ and $28 \%$ GC content, flanked by two $5.6-\mathrm{kb}$ imperfect imr1 repeats (imr1L, imr1R) with $29 \%$ GC content, and two pairs of $4.4-\mathrm{kb} \mathrm{dg}$ and $4.8-\mathrm{kb} \mathrm{dh}$ repeats $(\mathrm{dg} 1, \mathrm{dh} 1)$ of $33-34 \%$ GC content. A repeat of around $0.3 \mathrm{~kb}$, known as cen 253 (EMBL X13757), is found adjacent to the dh repeats. The maps of the other two centromeres have the same basic structure with central cnt regions flanked by imr repeats and by variable numbers of $\mathrm{dg}$ and $\mathrm{dh}$ repeats separated by cen 253 . Cnt $1,-2$ and -3 share $48 \%$ identity over a 1,405-bp region, and $\mathrm{dh} 1,-2$ and -3 share $48 \%$ identity over a 1,811-bp region. However, the most striking conservation is observed in the dg regions, which share $97 \%$ identity over a 1,780-bp region. This highly conserved segment represents an element that is essential for centromere function; deletion of this

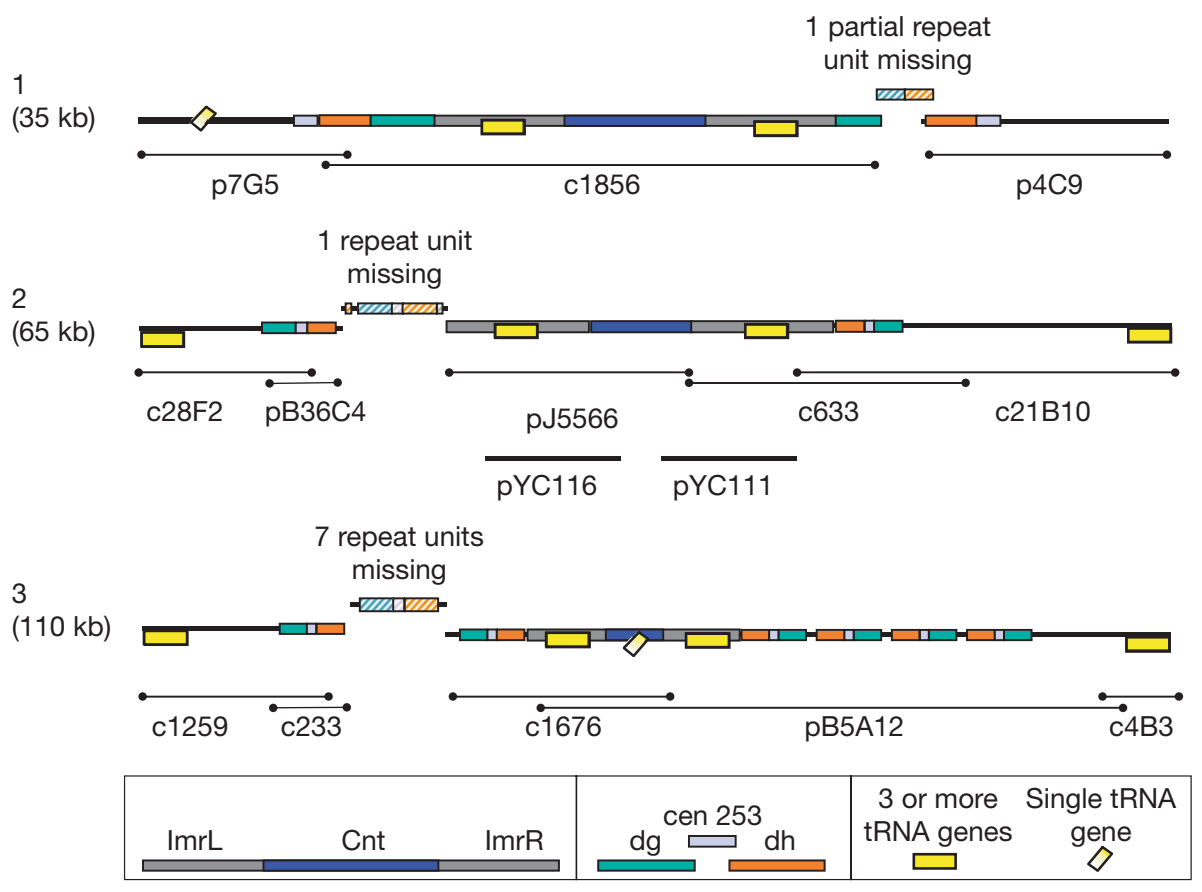

Figure 1 Schematic maps of the three $S$. pombe centromeres showing the repeated elements. The key is given at the bottom of the figure and the relevant clones are indicated under each centromere map. The maps are not drawn to scale. 
region from the dg repeat, termed the $\mathrm{K} / \mathrm{K}^{\prime \prime}$ repeat by the Clarke group, results in a complete loss of centromere activity in both mitosis and meiosis ${ }^{53}$. There must be a special mechanism to maintain such a high level of sequence conservation between the different centromeres. The total calculated lengths of centromeres 1 , 2 and 3 are respectively 35,65 and $110 \mathrm{~kb}$, inversely proportional to the lengths of the chromosomes at 5.7, 4.6 and 3.5 Mb. Possibly more extended centromeric regions are required for proper mitotic and meiotic behaviour when the chromosome arms are shorter. As noted above there are no protein-coding genes in the centromeric region but there are many tRNA genes (Fig. 1). tRNA clusters flank centromeres 2 and 3 and are also found within the imr regions of all three centromeres ${ }^{50}$. These tRNA genes might contribute to centromere function by defining domain boundaries important for centromere activity ${ }^{54}$.

The S. pombe centromeres are considerably longer than their S. cerevisiae equivalents, which contain a core region sufficient for centromere activity of only $120 \mathrm{bp}^{55,56}$ and a nuclease-protected region of $150-160 \mathrm{bp}$ including the 120 -bp conserved core ${ }^{57}$. It is not clear why $S$. pombe centromeres are $300-1,000$ times larger than their $S$. cerevisiae equivalents, but one possibility is that their kinetochore structures are different.

\section{Intergene regions}

The total intergene length distributions for $S$. pombe and $S$. cerevisiae are shown in Fig. 2. The length is calculated from the stop codon to the next start codon for tandemly oriented genes, from the start codon to the start codon for divergently oriented genes, and from the stop codon to the stop codon for convergently oriented genes. Intergenic regions in $S$. pombe have a mode of $423 \mathrm{bp}$ and a mean of $952 \mathrm{bp}$, both longer than the equivalent values for S. cerevisiae (200 and 515 bp respectively). Analysis of the divergent intergene regions reveals that pairs of upstream regions range in length from 200 to $2,100 \mathrm{bp}$, with a peak between 200 and 1,200 bp (Fig. 2). This is longer than the equivalent distributions in $S$. cerevisiae, which range from 200 to $900 \mathrm{bp}$, with a peak from 200 to $700 \mathrm{bp}$ (Fig. 2). Analysis of convergent intergene regions shows a peak in length for pairs of downstream regions of 200-800 bp for S. pombe and 100-500 bp for S. cerevisiae (Fig. 2). Therefore there is a smaller difference between the two yeasts for the intergenic regions between convergent genes (downstream regions) than for those between the divergent genes (upstream regions).

Several explanations can account for these results. The $5^{\prime}$ mRNA regions may be systematically longer in $S$. pombe than in $S$. cerevisiae, although there is no evidence for this. For example, the spacing between the TATA-box region and the transcriptional start in S. pombe is shorter than that in S. cerevisiae ${ }^{58,59}$. Alternatively, the promoter regions may be of greater complexity in $S$. pombe and therefore longer. Again there is no direct evidence to support this view, but there are other examples of more-extended organization of chromatin elements in S. pombe, including larger centromeres and regions of DNA replication origin ${ }^{60}$. The existence of truly intergenic spacer regions in $S$. pombe is supported by the identification of several $4-8-\mathrm{kb}$ extended gene-free regions, which fall outside the broad distribution of lengths associated with average intergenic regions. These are low complexity sequences with a $(G-C) /(G+C)$ strand switch ${ }^{61}$. There are about ten gene-free regions per chromosome, which are usually flanked by tandemly oriented genes. One of these gene-free regions, between SPAC4G8.03c and SPAC4G8.04, corresponds to a prominent meiotic DNA break site or cluster of sites (J. A. Young, R. W. Schreckhise and G. R. Smith, manuscript in preparation).

\section{Introns}

A total of 4,730 introns is distributed among $43 \%$ of S. pombe genes, with 15 being the largest number of introns found within a single gene (Table 2). Introns varied from 29 to 819 nucleotides long, with a mean length of 81 and a mode of 48 nucleotides. In S. cerevisiae, introns are much rarer, with only $5 \%$ of genes having introns. Most introns in S. pombe follow the rule of GT donor and AG acceptor, but there are three examples that have GC donors ${ }^{62}$. The average positions of introns within genes were assessed by mapping them with respect to the start and stop codons. This analysis does not take into account any introns in $5^{\prime}$ and $3^{\prime}$ untranslated regions. For the genes with 1-6 introns there is a $5^{\prime}$ bias from the values expected if introns were evenly distributed throughout the genes (Table 2). A $5^{\prime}$ bias is also seen in S. cerevisiae, where it has been hypothesized to be due to in vivo reverse transcription generating complementary DNAs primed from the $3^{\prime}$ ends of the mRNAs, followed by replacement of the original chromosomal gene with the cDNA by homologous recombination ${ }^{63}$. Because cDNAs are extended from their $3^{\prime}$ ends, there will be a tendency for introns at $5^{\prime}$ ends not to be
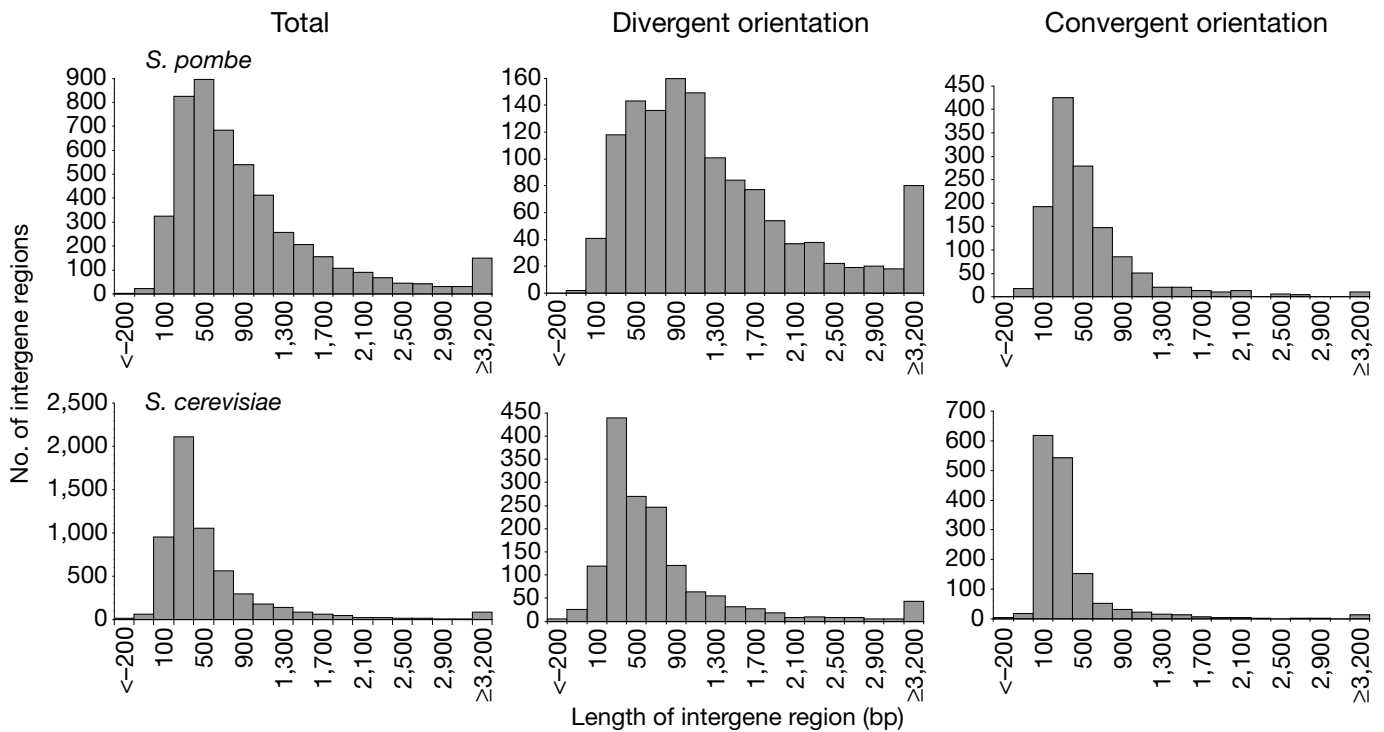

Figure 2 Intergene regions. Distribution of intergene regions given for all genes and for divergent and convergent pairs of genes, for both $S$. pombe and $S$. cerevisiae. A total of 4,890 intergene regions from $S$. pombe were analysed from a database prepared just before completion of the whole genome, and 5,788 intergene regions from $S$. cerevisiae were analysed. Histograms show the number of regions in 200-bp bins. 


\begin{tabular}{|c|c|c|c|c|c|c|c|c|}
\hline \multirow[t]{2}{*}{ Introns per gene } & \multirow[t]{2}{*}{ No. of genes } & \multirow[t]{2}{*}{ Mean gene length (bp) } & \multicolumn{6}{|c|}{ Position of introns* } \\
\hline & & & 1 & 2 & 3 & 4 & 5 & 6 \\
\hline 0 & 2,683 & 1,497 & - & - & - & - & - & - \\
\hline 1 & 996 & 1,426 & $0.26(0.50)$ & - & - & - & - & - \\
\hline 2 & 614 & 1,396 & $0.17(0.33)$ & $0.48(0.66)$ & - & - & - & - \\
\hline 3 & 324 & 1,588 & $0.13(0.25)$ & $0.37(0.50)$ & $0.63(0.75)$ & - & - & - \\
\hline 4 & 148 & 1,633 & $0.10(0.20)$ & $0.27(0.40)$ & $0.50(0.60)$ & $0.73(0.80)$ & - & - \\
\hline 5 & 70 & 1,603 & $0.08(0.17)$ & $0.22(0.33)$ & $0.37(0.49)$ & $0.56(0.66)$ & $0.77(0.83)$ & - \\
\hline 6 & 40 & 2,162 & $0.06(0.14)$ & $0.22(0.28)$ & $0.34(0.42)$ & $0.49(0.57)$ & $0.66(0.71)$ & $0.82(0.85)$ \\
\hline $7-15$ & 34 & 2,766 & - & - & - & - & - & - \\
\hline
\end{tabular}

The data set of 4,677 introns was prepared just before completion of the whole genome sequence.

* The mean position of introns, with the values in brackets representing the position if the introns were distributed evenly throughout the gene.

removed from the chromosomal genes. Of genes that have two or more introns, 614 have two introns, 324 have three, 148 have four, 70 have five and 40 have six (Table 2). Thus the number of genes having an extra intron decreases by about half as intron number increases from two to six per gene. These observations may be of relevance to speculations concerning the mechanisms by which introns are generated and removed ${ }^{64}$. The relatively large number of introns in $S$. pombe provides opportunities for alternative splicing to generate protein variants, which could have regulatory roles as well as increasing the range of protein types present in the cell ${ }^{65}$.

\section{Genome duplications and comparisons}

Comparisons of chromosomal sequences and searches for tracts of conserved gene order did not reveal evidence for large-scale genome duplications in S. pombe. This differs from reports for S. cerevisiae and Arabidopsis, which have suggested that both of these organisms have undergone some large-scale genome duplication ${ }^{4,66}$. However, blocks of duplicated sequence totalling about $50 \mathrm{~kb}$ retaining a conserved gene order can be found at the sub-telomeric regions of
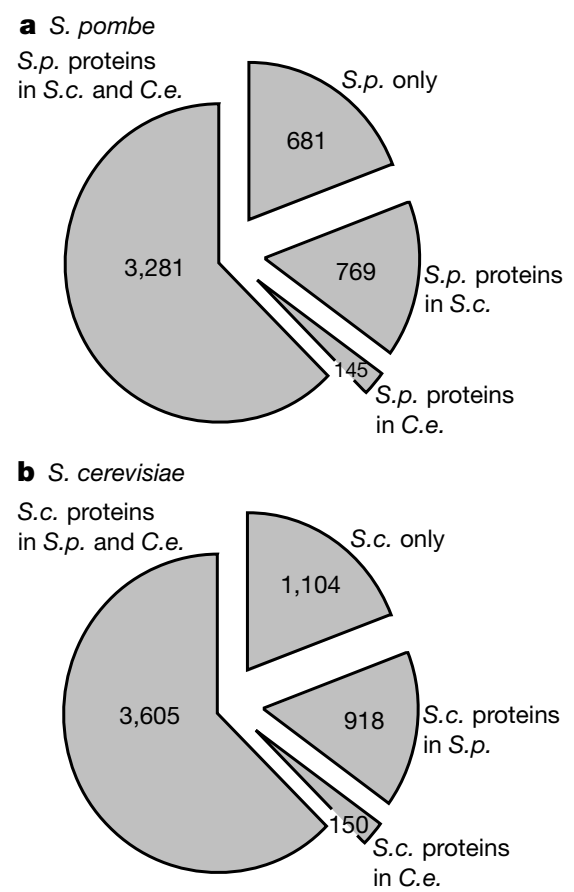

Figure 3 Comparison of proteins in S. pombe (S.p.), S. cerevisiae (S.c.) and C. elegans (C.e.). a, Pie chart comparing the homology of proteins of $S$. pombe with those of $S$. cerevisiae and $C$. elegans. b. Pie chart comparing the homology of proteins of S. cerevisiae with those of $S$. pombe and C. elegans. For example, S.p. proteins in S.c. and C.e. means $S$. pombe proteins with homologues found in $S$. cerevisiae and C. elegans. The absolute numbers of proteins are given for both yeasts. chromosomes I and II. Twenty-four genes (in groups of two or four) are $100 \%$ identical at the DNA level, and twenty of these are localized in sub-telomeric regions, suggesting frequent exchange of genetic information at these positions. Most of these genes code for proteins belonging to families specific to fission yeast and are predicted to be cell-surface proteins. Interestingly, in S. cerevisiae 7 of the 16 genes (in groups of two, three or four) that are $100 \%$ identical at the DNA level are also located in sub-telomeric regions. These gene products include members of the budding-yeast-specific PAU and COS families, which are also predicted to be cell-surface proteins ${ }^{39}$. In the highly plastic telomeric and sub-telomeric regions of malaria and several other protozoan parasites, genes coding for species-specific cell-surface proteins are also found, for example, the Var, Rifin and Stevor families of Plasmodium falciparum ${ }^{67}$. These data suggest that recombination events between telomeric regions may be a major mechanism involved in the generation of organism-specific cell-surface molecules. These molecules may also be of importance for cell identity and for processes that generate hypervariable cellsurface molecules relevant for self and non-self recognition.

We next compared the proteins of $S$. pombe with those of the unicellular eukaryote $S$. cerevisiae and the metazoan $C$. elegans (Fig. 3), using Blast $\mathrm{P}^{24}$ with a cutoff $E$-value of 0.001 and no lowcomplexity filtering. Excluding genes coded by the mitochondria and transposons, we used a data set of 4,876 proteins from $S$. pombe, 5,777 proteins from S. cerevisiae (Cerpep 14 May 2001; ftp://ftp. sanger.ac.uk/pub/yeast/SCreannotation/cerpep) and 19,622 proteins from C. elegans (ftp://ftp.sanger.ac.uk/pub/databases/wormpep). About two-thirds of the $S$. pombe proteins $(3,281)$ have homologues in common with both $S$. cerevisiae and C. elegans (Fig. 3). A smaller number, 769 (16\%), have homologues in S. cerevisiae but not in C. elegans and many fewer, $145(3 \%)$, have homologues in C. elegans but not in S. cerevisiae. A total of 681 proteins (14\%) seems to be unique to $S$. pombe. A comparison between $S$. cerevisiae and the other two organisms gave similar results, with $3,605(62 \%)$ of the proteins in common, $918(16 \%)$ found only in S. pombe and 150 (3\%) only in C. elegans, leaving 1,104 proteins (19\%) unique to $S$. cerevisiae. Thus, S. cerevisiae proteins with homologues only in S. pombe total 918 whereas the reverse comparison totals 769 (Fig. 3), indicating that there might be more gene duplications in S. cerevisiae, accounting for the extra proteins found in this organism.

To investigate gene duplication further, we carried out an 'all against all' comparison using the same protein data sets and NCBI BlastClust $^{68} \quad$ (ftp://ncbi.nlm.nih.gov/blast/documents/README. $\mathrm{bcl})$ to distinguish protein clusters from proteins represented uniquely. Of the 4,876 protein-coding genes of $S$. pombe, 4,515 have no other sequence relatives within the organism and can be considered unique. The remaining 361 are distributed among protein cluster groups with two or more members (Table 3). Using the same parameters in S. cerevisiae, 5,061 genes are unique and 716 fall into groups with two or more members (Table 3). This supports the idea that there is less gene redundancy than in $S$. cerevisiae, which may help functional analyses of those genes that are not duplicated in $S$. pombe. 


\section{Table 3 Gene duplication in S. pombe and S. cerevisiae}

\begin{tabular}{|c|c|c|}
\hline $\begin{array}{l}\text { Protein members } \\
\text { per cluster }\end{array}$ & $\begin{array}{l}\text { No. of clusters } \\
\text { in S. pombe }\end{array}$ & $\begin{array}{l}\text { No. of clusters } \\
\text { in S. cerevisiae }\end{array}$ \\
\hline 1 & 4,515 & 5,061 \\
\hline 2 & 124 & 256 \\
\hline 3 & 17 & 28 \\
\hline 4 & 8 & 11 \\
\hline 5 & 2 & 3 \\
\hline 6 & 1 & 1 \\
\hline 7 & 2 & 1 \\
\hline$>7$ & 0 & 3 \\
\hline Total no. of clusters & 4,669 & 5,364 \\
\hline Total no. of sequences & 4,876 & 5,777 \\
\hline
\end{tabular}

Protein clusters were identified with NCBI BlastClust using parameters S10.LO.9, as recommended by Y. Wolf (personal communication). We used databases of $4,876 \mathrm{~S}$. pombe proteins prepared just before completion of the genome sequence and of 5,777 S. cerevisiae proteins.

\section{Human disease genes}

To assess the usefulness of $S$. pombe for investigating the functions of genes related to human disease, we used the same method and dataset of human disease genes as that employed for analysis of the Drosophila genome ${ }^{69}$. Protein-coding genes of $S$. pombe were identified that generate products with similarities to proteins coded by 289 genes that are mutated, amplified or deleted in human disease. A total of $172 \mathrm{~S}$. pombe proteins have similarity with members of this data set of human disease proteins, and 122 of these have $E$ values greater than $1 \times 10^{-40}$. These values indicate that either they are not significant or they have only limited similarities with the equivalent human proteins, reflecting, for example, shared domains such as related protein-interacting regions or catalytic sites. However, despite this limitation, they may still be useful for investigating the biochemical activities and interactions of human disease proteins in S. pombe. The other $50 \mathrm{~S}$. pombe proteins (Tables 4 and 5) have $E$-values lower than $1 \times 10^{-40}$. The more significant similarities seen with this class mean that genes coding for these proteins are more likely to be useful for investigating not only the biochemical but also the biological functions of the human genes, and some could provide good models for studying the associated human disease pathways. The largest group of human disease-related genes are those implicated in cancer. There are 23 such genes (Table 4), and they are involved in DNA damage and repair, checkpoint controls, and the cell cycle, all processes involved in maintaining genomic stability. The cell cycle and checkpoint background of $S$. pombe make it a good model organism for studying these particular cancer disease pathways. Other categories that are also represented in $S$. pombe are those involved in metabolic (12 genes), neurological (13 genes), cardiac (1 gene) and renal (1 gene) disease (Table 5).

A similar analysis in S. cerevisiae identified 182 proteins with similarities to the human disease set, with most of the genes coding for these proteins being shared by the two yeasts. Only two of the genes (SPAC630.13c and SPBC530.12c), found in S. pombe but not $S$. cerevisiae, code for proteins with any significant similarity to human disease proteins. These are tuberous sclerosis 2 (TSC2), involved in cancer, and ceroid lipofuscinosis PPT1, involved in metabolism. Both yeasts seem to be similarly useful as model organisms for the study of human disease gene function, although their differing biologies may favour one organism for certain genes and the other organism for other genes.

\section{Protein domains}

Listed in Table 6 are the ten most frequent protein domains found in S. pombe, with 11 more domains of interest in the top 40 most frequent, as determined by InterPro matches ${ }^{70}$, together with the frequency of these domains for the other fully sequenced eukaryotic genomes. These domains are divided into three categories $(1-3)$.

The first category (1) consists of five domains found in the top ten most frequent domains in $S$. pombe that are also found in the top ten of at least four of the other eukaryotes. They are the ATP/GTP binding site, the WD40 repeat, the eukaryotic protein kinase catalytic core, the RNA binding region RNP-1, and the zinc finger $\mathrm{C} 2 \mathrm{H} 2$-type transcriptional activator. These universal and commonly exploited domains also feature highly in other eukaryotes. Because total gene number increases with the complexity of an organism, the proportion of these domains is approximately similar in each of the sequenced eukaryotic genomes. Energy utilization exploiting the ATP/GTP binding site, protein phosphorylation dependent on the catalytic protein kinase domain, and transcriptional activation using the zinc finger $\mathrm{C} 2 \mathrm{H} 2$ domain must define biochemical mechanisms that are readily exploited to generate new biological pathways.

In the second category (2), the domains are present in a similar absolute number in the eukaryotic genomes analysed. Amongst those more frequently found in this category are the BRCT, replication factor $\mathrm{C}$, minichromosome maintenance proteins (MCMs), Fizzy, DNA-directed DNA polymerase $\beta$ family and helicase C-terminal domains. Some of these are involved in core cell activities like DNA replication, DNA repair and cell-cycle progression, perhaps explaining why they are present in similar

\section{Table 4 Schizosaccharomyces pombe genes related to human cancer genes}

Human cancer gene

Xeroderma pigmentosum $\mathrm{D}$; XPD

Xeroderma pigmentosum $\mathrm{B}$; ERCC3

Hereditary non-polyposis colorectal cancer (HNPCC); $M S H 2$

Xeroderma pigmentosum F; XPF

Immunodeficiency; DNA ligase 1

HNPCC; PMS2

HNPCC; $M S H 6$

HNPCC; $M S H 3$

HNPCC; MLH1

Haematological Chediak-Higashi syndrome; $\mathrm{CHS} 1$

Darier-White disease; SERCA

Bloom syndrome; BLM

Ataxia telangiectasia; ATM

Xeroderma pigmentosum G: XPG

Tuberous sclerosis 2; TSC2

Immune bare lymphocyte; $A B C B 3$

Downregulated in adenoma; $D R A$

Diamond-Blackfan anaemia; RPS19

Cockayne syndrome I; CKN1

RAS

Cyclin-dependent kinase 4; CDK4

CHK2 protein kinase

AKT2

${ }^{*}$ Scores are:,$++++<1 \times 10^{-100} ;+++, 1 \times 10^{-40}$ to $1 \times 10^{-100}$.
Score

$++++$

$++++$

$++++$

++++
++++

$++++$

++++
++++

++++
++++

$++++$

+rt+

++++
++++

$++++$

$++++$

$++++$

+++
+++

$+++$

$+++$

+++
+++

$++$

$+++$

+++
+++
S. pombe gene/product

rad15, rhp3

$\operatorname{rad} 25$

msh2

rad16, rad10, rad20, swi9

cdc17

pms1

msh6

swi4

mlh1

pgak

hus2, rqh1, rad12

tel1

$\operatorname{rad} 13$

-

rps19

-

cdc2

cds1

pck2, sts6, pkc1
Systematic name SPAC1D4.12 SPAC17A5.06 SPBC24C6.12C SPCC970.01 SPAC57A10.13C SPAC19G12.02C SPCC285.16C SPAC8F11.03 SPBC1703.04 SPBC28E12.06C SPBC31E1.02C SPAC2G11.12 SPCC23B6.03C SPBC3E7.08C SPAC630.13C SPBC9B6.09C SPAC869.05C SPBC649.02 SPBC577.09 SPAC17H9.09C SPBC11B10.09 SPCC18B5.11C SPBC12D12.04C 


\begin{tabular}{|c|c|c|c|c|}
\hline Human disease gene & Disease & Score $^{*}$ & S. pombe gene/product & Systematic name \\
\hline Wilson disease; ATP7B & Metabolic & ++++ & P-type copper ATPase & SPBC29A3.01 \\
\hline Non-insulin-dependent diabetes; PCSK1 & Metabolic & ++++ & krp1, kinesin related & SPAC22E12.09C \\
\hline Hyperinsulinism; $A B C C 8$ & Metabolic & ++++ & $\mathrm{ABC}$ transporter & SPAC3F10.11C \\
\hline G6PD deficiency; G6PD & Metabolic & ++++ & zwf1 GP6 dehydrogenase & SPAC3A12.18 \\
\hline Citrullinaemia type I; ASS & Metabolic & ++++ & Argininosuccinate synthase & SPBC428.05C \\
\hline Wernicke-Korsakoff syndrome; TKT & Metabolic & +++ & Transketolase & SPBC2G5.05 \\
\hline Variegate porphyria; $P P O X$ & Metabolic & +++ & Protoporphyrinogen oxidase & SPAC1F5.07C \\
\hline Maturity-onset diabetes of the young (MODY2); GCK & Metabolic & +++ & hxk1, hexokinase & SPAC24H6.04 \\
\hline Gitelman's syndrome; SLC12A3 & Metabolic & +++ & CCC Na-K-Cl transporter & SPBC18H10.16 \\
\hline Cystinuria type $1 ;$ SLC3A1 & Metabolic & +++ & $\alpha$-glucosidase & SPBC1683.07 \\
\hline Cystic fibrosis; $A B C C 7$ & Metabolic & +++ & ABC transporter & SPBC359.05 \\
\hline Bartter's syndrome; SLC12A1 & Metabolic & +++ & CCC Na-K-Cl transporter & SPBC18H10.16 \\
\hline Menkes syndrome; ATP7A & Neurological & ++++ & P-type copper ATPase & SPBC29A3.01 \\
\hline Deafness, hereditary; MYO15 & Neurological & ++++ & my051 class $\vee$ myosin & SPBC2D10.14C \\
\hline Zellweger syndrome; PEX1 & Neurological & +++ & AAA-family ATPase & SPCC553.03 \\
\hline Thomsen disease; CLCN1 & Neurological & +++ & $\mathrm{CIC}$ chloride channel & SPBC19C7.11 \\
\hline Spinocerebellar ataxia type 6 (SCA6); CACNA1A & Neurological & +++ & VIC sodium channel & SPAC6F6.01 \\
\hline Myotonic dystrophy; DM1 & Neurological & +++ & orb6 Ser/Thr protein kinase & SPAC821.12 \\
\hline McCune-Albright syndrome; GNAS1 & Neurological & +++ & gpa1 guanine nucleotide binding & SPBC24C6.06 \\
\hline Lowe's oculocerebrorenal syndrome; OCRL & Neurological & +++ & PIP phosphatase & SPBC2G2.02 \\
\hline Dents; CLCN5 & Neurological & +++ & CIC chloride channel & SPBC19C7.11 \\
\hline Coffin-Lowry; RPS6KA3 & Neurological & +++ & Ser/Thr protein kinase & SPCC24B10.07 \\
\hline Angelman; UBE3A & Neurological & +++ & Ubiquitin-protein ligase & SPBP8B7.27 \\
\hline Amyotrophic lateral sclerosis; SOD1 & Neurological & +++ & sod1, superoxide dismutase & SPAC821.10C \\
\hline Oguchi type 2; RHKIN & Neurological & +++ & Ser/Thr protein kinase & SPCC24B10.07 \\
\hline Familial cardiac myopathy; $M Y H 7$ & Cardiac & ++++ & myo2, myosin ॥ & SPCC645.05C \\
\hline Renal tubular acidosis; ATP6B1 & Renal & ++++ & V-type ATPase & SPAC637.05C \\
\hline
\end{tabular}

* Scores are:,$++++<1 \times 10^{-100} ;+++, 1 \times 10^{-40}$ to $1 \times 10^{-100}$.

absolute number regardless of genome size ${ }^{71}$. Systematic searches for other domains present in similar absolute numbers in genomes of all eukaryotes might identify other, at present unrecognized, functions involved in similar core cell activities.

The third category (3) includes domains whose occurrence rises dramatically with increasing genome size within the Metazoa. This category includes the $\mathrm{SH} 3, \mathrm{PH}$ and tyrosine/dual-specificity phosphatase domains. These are involved in intra- and intercellular signalling pathways, which might be expected to become increasingly elaborate as multicellular complexity increases ${ }^{69,71}$.

Two other domains in the top ten for both the yeasts are the sugar and $\mathrm{ABC}$ transporters (Table 6). S. cerevisiae has significantly more of these domains and the amino-acid permease domain than does $S$. pombe $e^{72}$, which may explain why it is a more versatile organism, growing on a greater range of media. The $\mathrm{Zn}(\mathrm{ll}) \mathrm{Cys}(6)$ transcription- factor domain is found only in the two yeasts, supporting the idea that it is specific to fungi. The chromodomain is found more frequently in $S$. pombe-seven examples compared with two in S. cerevisiae-possibly reflecting differences in higher-order chromatin structure.

\section{Defining the eukaryotic cell}

The genome sequence of $S$. pombe increases the range of available complete eukaryotic genome sequences to two unicellular free-living organisms (S. cerevisiae and S. pombe), one plant (Arabidopsis), and three metazoans (C. elegans, Drosophila and humans). This range of organisms allows a comparison between eukaryotic and prokaryotic genomes (represented by 37 bacteria and 8 archaea), with the intention of identifying those genes important for eukaryotic cell organization. We have made an

Table 6 Protein domain analysis and comparison with other eukaryotes

\begin{tabular}{|c|c|c|c|c|c|c|c|c|c|c|c|c|c|c|}
\hline \multirow{2}{*}{$\begin{array}{l}\text { Interpro } \\
\text { accession no. }\end{array}$} & \multicolumn{2}{|c|}{ S. pombe } & \multicolumn{2}{|c|}{ S. cerevisiae } & \multicolumn{2}{|c|}{ H. sapiens } & \multicolumn{2}{|c|}{ D. melanogaster } & \multicolumn{2}{|c|}{ C. elegans } & \multicolumn{2}{|c|}{ A. thaliana } & \multicolumn{2}{|l|}{ Interpro name } \\
\hline & Proteins & Rank & Proteins & Rank & Proteins & Rank & Proteins & Rank & Proteins & Rank & Proteins & Rank & & \\
\hline IPR001687 & 213 & 1 & 267 & 1 & 436 & 5 & 231 & 4 & 191 & 7 & 331 & 5 & ATP/GTP-binding site motif A (Ploop) & 1 \\
\hline IPR001680 & 114 & 2 & 97 & 3 & 277 & 8 & 183 & 5 & 102 & 19 & 210 & 10 & G protein $\beta$ WD40 repeats & 1 \\
\hline IPR000719 & 111 & 3 & 119 & 2 & 579 & 3 & 377 & 2 & 450 & 2 & 1,049 & 1 & Eukaryotic protein kinase & 1 \\
\hline IPR000504 & 80 & 4 & 61 & 5 & 307 & 7 & 182 & 6 & 97 & 21 & 255 & 8 & RNA binding region RNP1 & 1 \\
\hline IPR001650 & 67 & 5 & 63 & 4 & 155 & 20 & 101 & 17 & 80 & 27 & 148 & 13 & Helicase C-terminal domain & 2 \\
\hline IPR001841 & 44 & 6 & 33 & 12 & 215 & 15 & 120 & 11 & 126 & 12 & 379 & 4 & RING finger & - \\
\hline IPR001440 & 38 & 7 & 33 & 12 & 150 & 21 & 92 & 18 & 46 & 43 & 125 & 17 & TPR repeat & - \\
\hline IPR001066 & 36 & 8 & 46 & 8 & 44 & 64 & 45 & 34 & 55 & 37 & 98 & 26 & Sugar transporter & - \\
\hline IPR001617 & 33 & 9 & 42 & 9 & 75 & 40 & 67 & 28 & 61 & 36 & 103 & 25 & ABC transporter family & - \\
\hline IPR000822 & 32 & 10 & 51 & 7 & 712 & 2 & 403 & 1 & 154 & 10 & 115 & 20 & Zinc finger, $\mathrm{C} 2 \mathrm{H} 2$ type & 1 \\
\hline IPR001357 & 14 & 23 & 10 & 30 & 24 & 82 & 17 & 61 & 25 & 60 & 17 & 83 & BRCT domain & 2 \\
\hline IPR000862 & 8 & 29 & 9 & 31 & 8 & 98 & 9 & 68 & 6 & 79 & 13 & 87 & Replication factor C conserved domain & 2 \\
\hline IPR002064 & 5 & 32 & 5 & 35 & 4 & 102 & 6 & 70 & 3 & 82 & 5 & 95 & DNA directed DNA polymerase family $\beta$ & 2 \\
\hline IPR001208 & 6 & 31 & 6 & 34 & 12 & 94 & 13 & 64 & 5 & 80 & 8 & 92 & MCM family & 2 \\
\hline IPR000002 & 5 & 32 & 3 & 37 & 3 & 103 & 4 & 72 & 2 & 83 & 6 & 94 & FIZZY/CDC20 domain & 2 \\
\hline IPR001452 & 21 & 16 & 23 & 18 & 220 & 14 & 82 & 23 & 62 & 35 & 3 & 97 & Src homology 3 (SH3) domain & 3 \\
\hline IPR001849 & 21 & 16 & 26 & 16 & 253 & 11 & 89 & 22 & 75 & 31 & 27 & 73 & $\mathrm{PH}$ domain & 3 \\
\hline IPR000387 & 9 & 28 & 11 & 29 & 112 & 29 & 47 & 40 & 110 & 16 & 21 & 79 & $\begin{array}{l}\text { Tyrosine-specific protein phosphatase and } \\
\text { dual-specificity protein phosphatase family }\end{array}$ & 3 \\
\hline IPR001138 & 27 & 13 & 52 & 6 & 0 & NA & 0 & NA & 0 & NA & 0 & NA & Fungal transcriptional regulatory protein & - \\
\hline IPR002293 & 21 & 16 & 32 & 13 & 43 & 65 & 36 & 45 & 32 & 54 & 65 & 42 & Permease for amino acids and related compounds & - \\
\hline IPR000953 & 7 & 30 & 2 & 38 & 26 & 80 & 20 & 58 & 15 & 70 & 24 & 76 & Chromodomain & - \\
\hline
\end{tabular}

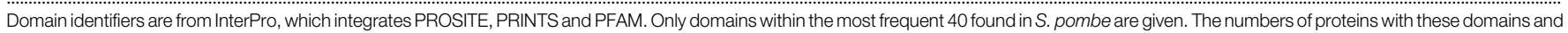
their ranking is given for $S$. pombe and the other eukaryotes listed. At the right end of the table is a classification of 1-3; see text for an explanation. NA, not applicable. 
Table 7 Identifying conserved genes important for defining the eukaryotic cell and multicellularity

\begin{tabular}{|c|c|c|c|c|}
\hline Similarity & No. of genes & $\geq 20 \%$ & $\geq 15 \%$ & $\geq 12 \%$ \\
\hline \multicolumn{5}{|c|}{ (a) Genes defining eukaryotic organization } \\
\hline $\begin{array}{l}50 \% \\
45 \% \\
40 \%\end{array}$ & $\begin{array}{l}184 \\
245 \\
311\end{array}$ & $\begin{array}{r}62 \\
86 \\
113\end{array}$ & $\begin{array}{l}47 \\
63 \\
81\end{array}$ & $\begin{array}{l}41 \\
55 \\
70\end{array}$ \\
\hline
\end{tabular}

(b) Genes defining multicellularity

$50 \%$

$45 \%$

$40 \%$

397
511
647
1

3 binding proteins and another may be localized in the nucleus (SPCP1E11.08). The second group includes two Rps and six Rpl proteins, components of the $40 \mathrm{~S}$ and $60 \mathrm{~S}$ ribosomal subunits respectively; these eight proteins may contribute to differences in protein translation between prokaryotes and eukaryotes.

Two further groups in Table 8 are relevant for the more elaborate organization and compartmentation of eukaryotic cells. One consists of cytoskeletal proteins, the actins Act1 and Act2, the tubulins Nda2, Nda3 and Tub1, and the cytoskeleton-associated proteins Arp2 and Cdc42. The actin and tubulin polymers provide not only internal structure but also the means for transport of components and information from one region of the cell to another, important matters given the increased size of eukaryotic cells. The bacterial FtsA, Hsp70 and FtsZ proteins have structures with similarities respectively to actin and tubulin but only very limited primary sequence similarities ${ }^{73-75}$. Arp2 is an actin-related protein required for actin organization, and the Cdc42 GTPase is a signalling molecule important for cell shape and for communicating signals from the cytoskeleton. One protein (SPAC926.07c) is predicted to be a dynein light chain. The second group consists of GTP binding proteins and their regulators Ypt1, -2, -3 and -7, Arf1, Aps1, Gdi1 and Sar1, which are required for membrane transport. Membranebound organelles and structures are characteristic features of eukaryotic cells, and membrane fusion and fragmentation are important in organelle formation and function. Cam1 (calmodulin) is a protein that exploits compartmentalization of $\mathrm{Ca}^{2+}$ to regulate cellular processes. One protein (SPBC1539.08) is a putative ADP ribosylation factor and may be involved in transport.

A small group (Table 8) includes cell-cycle and checkpoint control proteins. The Cdc2 protein kinase (Cdc28 in S. cerevisiae) is a cyclin-dependent kinase (CDK) controlling the onset of S-phase and mitosis in the two yeasts, with closely related CDKs controlling these cell-cycle transitions in other eukaryotes. The CDK system for cell-cycle control evolved with the appearance of eukaryotic cells, whose cell cycle differs from prokaryotes in two ways: DNA synthesis, which uses multiple origins of replication, and mitosis, which brings about chromosome segregation. It has been argued that, in the primeval eukaryote, there was a single CDK that underwent a monotonic change during the cell cycle, initiating $S$ phase early in the cycle at a low activity and mitosis late in the cycle at a high activity ${ }^{76}$. Two checkpoint proteins, $\operatorname{Rad} 24$ and $\operatorname{Rad} 25$, are 14-3-3 proteins thought to regulate the Cdc25 phosphatase controlling the $\mathrm{Cdc} 2 \mathrm{CDK}^{77}$. If DNA becomes damaged then these checkpoint proteins prevent the onset of mitosis until the damage is repaired. This pathway is essential for maintaining genomic stability and seems to be characteristic of eukaryotic cells.

Three further groups reflect biochemical processes that are important in eukaryotic cell regulation. The first group consists of Lsm 2 and Smd2, which are required for RNA splicing. The second group consists of the Ubc, Ubi and Ubl proteins together with Uip1 and Pad1 (Table 8), all required to bring about controlled proteolysis of proteins. A further protein putatively involved in proteolysis is a prohibitin complex subunit (SPAC1782.06c). The for nuclear membrane transport. One putative protein in category (SPAC890.07c) is possibly involved in export of mRNA subunits. The first group includes the $\mathrm{H} 3$ and $\mathrm{H} 4$ core histone proteins required for packaging DNA into nucleosomes, the Hda1 histone deacetylase, which suggests histone acetylation is critical for eukaryotic chromatin, and the Ran GTPase Spi1, a key element

\begin{abstract}
proteolysis is a prohibitin complex subunit (SPAC1782.06c). The
\end{abstract}

\begin{tabular}{|c|c|c|c|c|c|c|c|c|}
\hline Nucleus & Ribosomal & Cytoskeleton & Compartmentation & Cell cycle & Splicing & Proteolysis & $\begin{array}{c}\text { Kinase/ } \\
\text { phosphatase }\end{array}$ & Miscellaneous \\
\hline h3.1 & rpl18 & act1 & ypt1 & cdc2 & Ism2 & ubc13 & cka1 & SPBC24C6.11 \\
\hline h3.2 & rpl27 & act2 & ypt2 & $\operatorname{rad} 24$ & smd2 & ubc4 & dis2 & SPBP8B7.24C \\
\hline h3.3 & rpl27A & arp2 & ypt3 & rad25 & & ubi1 & hhp1 & \\
\hline h4.1 & rpl29 & cdc42 & ypt7 & & & ubi4 & ppa1 & \\
\hline h4.2 & rpl7A & nda2 & aps1 & & & ubl1 & ppa2 & \\
\hline h4.3 & rpl7 & nda3 & arf1 & & & uep1 & ppe1 & \\
\hline hda1 & rps3A & tub1 & cam1 & & & hus5 & sds21 & \\
\hline spi1 & rps21 & SPAC926.07C & gdi1 & & & pad1 & SPBC26H8.05C & \\
\hline SPAC890.07C & & & sar1 & & & rhp6 & SPAC22H10.04 & \\
\hline SPCP1E11.08 & & & SPBC1539.08 & & & SPAC1782.06C & & \\
\hline
\end{tabular}


third group consists of protein kinases and phosphatases, and includes Cka1, Dis2, Hhpt, Ppa1, Ppa2, Ppe1 and Sds21 and putative serine/threonine protein phosphatases (SPAC22H10.04 and $\mathrm{SPBC} 26 \mathrm{H} 8.05 \mathrm{c}$ ). The presence of these three regulatory processes unique to eukaryotic cells allows protein levels and activities to be specifically and rapidly changed without relying on changes in transcription rate. In prokaryotic cells, gene regulation often operates through changes in transcription rate, followed by dilution of remaining proteins as a consequence of rapid cellular growth. The slower growth rates of eukaryotic cells means that mechanisms in addition to dilution by growth are required to modulate protein activity; these mechanisms may be provided by RNA splicing, proteolysis and phosphorylation.

Two genes code for a putative zinc-finger protein (SPBC24C6.11) with a possible role in cell polarity and a putative autophagy protein (SPBP8B7.24c) that may mediate attachment of autophagosomes to microtubules. Extension of this analysis at different thresholds of similarity should identify further proteins of unknown function that are important for eukaryotic cell organization.

We performed a similar analysis to identify highly conserved genes that may be important for maintaining multicellular eukaryotic organization (Table $7 \mathrm{~b}$ ). We compared the proteins in prokaryotes and in S. cerevisiae and S. pombe, which are all unicellular, with those of C. elegans, Drosophila, Arabidopsis and humans, which are all multicellular. The same thresholds were used to identify those proteins that are highly conserved in the four multicellular eukaryotes $(50 \%, 45 \%$ and $40 \%)$ and to identify which of these proteins were not found to be highly conserved in the unicellular organisms $(20 \%, 15 \%$ and $12 \%)$. The number of genes coding for proteins that fall into these categories was very small: one to three depending on the thresholds used. These genes code a putative transcription factor, an RNA-binding protein and a selenium-binding protein.

As more sequences become available, the groups of genes we have identified as being important for eukaryotic and multicellular organization will inevitably be modified. However, our results allow us to speculate on the evolutionary transitions from prokaryotes to eukaryotes and to multicellularity. The transition to multicellularity may not have required the evolution of many new genes, absent from unicellular organisms. The pathways necessary for multicellular organization could already have been in existence in unicellular eukaryotes. For example, intercellular signalling may have been solved by the sexual needs of primeval, single-celled eukaryotes to seek out and identify an appropriate mating partner. Once signalling between cells had evolved, it could be readily exploited to generate the signalling pathways required for multicellular organization. The highly conserved genes specific to eukaryotes may be necessary for eukaryotic cell organization to be generated. In contrast, the transition from unicellularity to multicellularity may not have required many new genes. Instead it may have used genes already present in unicellular eukaryotes, perhaps by the shuffling of functional domains, to give rise to new combinations, which allowed the development of pathways required for the evolution of multicellularity ${ }^{2,69,71,78}$. If these speculations are correct, they imply that the evolutionary transition from unicellular prokaryotic to unicellular eukaryotic life may have been more complex than the transition to multicellular life. This might provide some explanation as to why it took around 2,300 million years (Myr) to evolve from the first prokaryote to the first eukaryote (thought to have arisen about 3,800 Myr and 1,500 Myr ago, respectively) but only $500 \mathrm{Myr}$ for the evolution of the first multicellular organisms, which arose about 1,000 Myr ago. Further analyses and comparisons should continue to be illuminating about this interesting question of which genes define eukaryotic cells and which define multicellular organisms.

Received 16 October 2001; accepted 7 January 2002.

1. Goffeau, A. et al. The yeast genome directory. Nature 387 (suppl.), 1-105 (1997).
2. The C. elegans Sequencing Consortium. Genome sequence of the nematode C. elegans: a platform for investigating biology. Science 282, 2012-2018 (1998).

3. Adams, M. D. et al. The genome sequence of Drosophila melanogaster. Science 287, 2185-2195 (2000).

4. The Arabidopsis Genome Initiative. Analysis of the genome sequence of the flowering plant Arabidopsis thaliana. Nature 408, 796-815 (2000).

5. Lander, E. S. et al. Initial sequencing and analysis of the human genome. Nature 409, 860-921 (2001).

6. Venter, J. C. et al. The sequence of the human genome. Science 291, 1304-1351 (2001).

7. Sipiczki, M. Where does fission yeast sit on the tree of life? Genome Biol. 1, 1011.1-1011.4 (2000).

8. Heckman, D. S. et al. Molecular evidence for the early colonization of land by fungi and plants. Science 293, 1129-1133 (2001).

9. Leupold, U. Die Verebung von Homothallie und Heterothallie bei Schizosaccharomyces pombe. C.R Lab. Carlsberg 24, 381-475 (1950).

10. Mitchison, J. M. The growth of single cells. I. Schizosaccaromyces pombe. Expl. Cell Res. 13, 244-262 (1957).

11. Fantes, P. \& Beggs, J. The Yeast Nucleus (Oxford Univ. Press, Oxford, 2000).

12. Davis, L. \& Smith, G. R. Meiotic recombination and chromosome segregation in Schizosaccharomyces pombe. Proc. Natl Acad. Sci. USA 98, 8395-8402 (2001).

13. Humphrey, T. DNA damage and cell cycle control in Schizosaccharomyces pombe. Mutat. Res. 451, 211-226 (2000).

14. Smith, C. L. et al. An electrophoretic karyotype for Schizosaccharomyces pombe by pulsed field gel electrophoresis. Nucleic Acids Res. 15, 4481-4491 (1987).

15. Lang, B. F., Cedergren, R. \& Gray, M. W. The mitochondrial genome of the fission yeast, Schizosaccharomyces pombe. Sequence of the large-subunit ribosomal RNA gene, comparison of potential secondary structure in fungal mitochondrial large-subunit rRNAs and evolutionary considerations. Eur. J. Biochem. 169, 527-537 (1987).

16. Schaak, J., Mao, J. \& Soll, D. The 5.8S RNA gene sequence and the ribosomal repeat of Schizosaccharomyces pombe. Nucleic Acids Res. 10, 2851-2864 (1982).

17. Hoheisel, J. D. et al. High resolution cosmid and P1 maps spanning the $14 \mathrm{Mb}$ genome of the fission yeast S. pombe. Cell 73, 109-120 (1993).

18. Mizukami, T. et al. A $13 \mathrm{~kb}$ resolution cosmid map of the $14 \mathrm{Mb}$ fission yeast genome by nonrandom sequence-tagged site mapping. Cell 73, 121-132 (1993).

19. Harris, D. \& Murphy, L. in Genomics Protocols (eds Starkey, M. \& Elaswarapu, R.) 217-234 (Humana, Tokawa, New Jersey, 2001)

20. Bonfield, J. K., Smith, K. \& Staden, R. A new DNA sequence assembly program. Nucleic Acids Res. 23, 4992-4999 (1995)

21. Bairoch, A. \& Apweiler, R. The SWISS-PROT protein sequence data bank and its supplement TrEMBL in 1999. Nucleic Acids Res. 27, 49-54 (1999).

22. Stoesser, G., Tuli, M. A., Lopez, R. \& Sterk, P. The EMBL nucleotide sequence database. Nucleic Acids Res. 27, 18-24 (1999)

23. Bateman, A. et al. Pfam 3.1: 1313 multiple alignments and profile HMMs match the majority of proteins. Nucleic Acids Res. 27, 260-262 (1999).

24. Altschul, S. F., Gish, W., Miller, W., Myers, E. W. \& Lipman, D. J. Basic local alignment search tool. J. Mol. Biol. 215, 403-410 (1990).

25. Sonnhammer, E. L. \& Durbin, R. A workbench for large-scale sequence homology analysis. Comput. Appl. Biosci. 10, 301-307 (1994).

26. Pearson, W. R. \& Lipman, D. J. Improved tools for biological sequence comparison. Proc. Natl Acad. Sci. USA 85, 2444-2448 (1988).

27. Birney, E., Thompson, J. D. \& Gibson, T. J. PairWise and SearchWise: finding the optimal alignment in a simultaneous comparison of a protein profile against all DNA translation frames. Nucleic Acids Res. 24, 2730-2739 (1996).

28. Rutherford, K. et al. Artemis: sequence visualization and annotation. Bioinformatics 16, 944-945 (2000). 29. Morimyo, M. et al. in Biodefence Mechanisms against Environmental Stress (eds Ozawa, T., Hori, T. \& Tatsumi, K.) 115-123 (Kondansa, Tokyo \& Springer, Heidelberg, 1998).

30. Costanzo, M. C. et al. The yeast proteome database (YPD) and Caenorhabditis elegans proteome database (WormPD): comprehensive resources for the organization and comparison of model organism protein information. Nucleic Acids Res. 28, 73-76 (2000).

31. Cherry, J. M. et al. SGD: Saccharomyces genome database. Nucleic Acids Res. 26, $73-79$ (1998).

32. Mewes, H. W. et al. MIPS: a database for genomes and protein sequences. Nucleic Acids Res. 28, 37-40 (2000)

33. Lowe, T. M. \& Eddy, S. R. tRNAscan-SE: a program for improved detection of transfer RNA genes in genomic sequence. Nucleic Acids Res. 25, 955-964 (1997).

34. Blandin, G. et al. Genomic exploration of the hemiascomycetous yeasts: 4 . The genome of Saccharomyces cerevisiae revisited. FEBS Lett. 487, 31-36 (2000).

35. Wood, V., Rutherford, K. M., Ivens, A., Rajandream, M.-A. \& Barrell, B. A re-annotation of the Saccharomyces cerevisiae genome. Comp. Funct. Genom. 2, 143-154 (2001).

36. Kaneko, T. et al. Complete genome structure of the nitrogen-fixing symbiotic bacterium Mesorhizobium loti (supplement). DNA Res. 7, 381-406 (2000).

37. Hutchison, C. A. et al. Global transposon mutagenesis and a minimal Mycoplasma genome. Science 286, 2165-2169 (1999).

38. Deckert, G. et al. The complete genome of the hyperthermophilic bacterium Aquifex aeolicus. Nature 392, 353-358 (1998).

39. Goffeau, A. et al. Life with 6000 genes. Science 274, 546, 563-567 (1996).

40. Barnitz, J. T., Cramer, J. H., Rownd, R. H., Cooley, L. \& Soll, D. Arrangement of the ribosomal RNA genes in Schizosaccharomyces pombe. FEBS Lett. 143, 129-132 (1982).

41. Mao, J. et al. The 5S RNA genes of Schizosaccharomyces pombe. Nucleic Acids Res. 10, 487-500 (1982). 42. Carr, A. M., MacNeill, S. A., Hayles, J. \& Nurse, P. Molecular cloning and sequence analysis of mutant alleles of the fission yeast $\mathrm{cdc} 2$ protein kinase gene: implications for $\mathrm{cdc}^{+}$protein structure and function. Mol. Gen. Genet. 218, 41-49 (1989).

43. Kim, J. M., Vanguri, S., Boeke, J. D., Gabriel, A. \& Voytas, D. F. Transposable elements and genome organization: a comprehensive survey of retrotransposons revealed by the complete Saccharomyces cerevisiae genome sequence. Genome Res. 8, 464-478 (1998).

44. Ashburner, M. et al. An exploration of the sequence of a 2.9-Mb region of the genome of Drosophila melanogaster: the Adh region. Genetics 153, 179-219 (1999).

45. Gu, Z., Wang, H., Nekrutenko, A. \& Li, W. H. Densities, length proportions, and other distributional 
features of repetitive sequences in the human genome estimated from 430 megabases of genomic sequence. Gene 259, 81-88 (2000).

46. Egel, R. Reorientation of the distal region in linkage group IIR of fission yeast. Curr. Genet. 24, 179180 (1993)

47. Chikashige, Y. et al. Composite motifs and repeat symmetry in S. pombe centromeres: direct analysis by integration of NotI restriction sites. Cell 57, 739-751 (1989).

48. Murakami, S., Matsumoto, T., Niwa, O. \& Yanagida, M. Structure of the fission yeast centromere cen3: direct analysis of the reiterated inverted region. Chromosoma 101, 214-221 (1991).

49. Clarke, L. \& Baum, M. P. Functional analysis of a centromere from fission yeast: a role for centromerespecific repeated DNA sequences. Mol. Cell. Biol. 10, 1863-1872 (1990).

50. Takahashi, K., Murakami, S., Chikashige, Y., Niwa, O. \& Yanagida, M. A large number of tRNA gene are symmetrically located in fission yeast centromeres. J. Mol. Biol. 218, 13-17 (1991).

51. Nakaseko, Y., Adachi, Y., Funahashi, S.-I., Niwa, O. \& Yanagida, M. Chromosome walking shows a highly homologous repetitive sequence present on all the centromere regions of fission yeast. $E M B O J$. 5, 1011-1021 (1986).

52. Fishel, B., Amstutz, H., Baum, M., Carbon, J. \& Clarke, L. Structural organization and functional analysis of centromeric DNA in the fission yeast Schizosaccharomyces pombe. Mol. Cell. Biol. 8, 754763 (1988).

53. Baum, M., Ngan, V. K. \& Clarke, L. The centromeric K-type repeat and the central core are together sufficient to establish a functional Schizosaccharomyces pombe centromere. Mol. Biol. Cell 5, 747-761 (1994).

54. Partridge, J. F., Borgstrom, B. \& Allshire, R. C. Distinct protein interaction domains and protein spreading in a complex centromere. Genes Dev. 14, 783-791 (2000).

55. Hyman, A. A. \& Sorger, P. K. Structure and function of kinetochores in budding yeast. Annu. Rev. Cell Dev. Biol. 11, 471-495 (1995)

56. Hieter, P. et al. Functional selection and analysis of yeast centromeric DNA. Cell 42, 913-921 (1985)

57. Funk, M., Hegemann, J. H. \& Philippsen, P. Chromatin digestion with restriction endonucleases reveals $150-160$ bp of protected DNA in the centromere of chromosome XIV in Saccharomyces cerevisiae. Mol. Gen. Genet. 219, 153-160 (1989).

58. Russell, P. R. Transcription of the triose-phosphate-isomerase gene of Schizosaccharomyces pombe initiates from a start point different from that in Saccharomyces cerevisiae. Gene 40, 125-130 (1985).

59. Nagawa, F. \& Fink, G. R. The relationship between the "TATA" sequence and transcription initiation sites at the HIS4 gene of Saccharomyces cerevisiae. Proc. Natl Acad. Sci. USA 82, 8557-8561 (1985).

60. Gomez, M. \& Antequera, F. Organization of DNA replication origins in the fission yeast genome. EMBO J. 18, 5683-5690 (1999).

61. Lobry, J. R. Asymmetric substitution patterns in the two DNA strands of bacteria. Mol. Biol. Evol. 13, 660-665 (1996).

62. Maniatis, T. \& Reed, R. The role of small nuclear ribonucleoprotein particles in pre-mRNA splicing. Nature 325, 673-678 (1987)

63. Fink, G. R. Pseudogenes in yeast? Cell 49, 5-6 (1987).

64. Robertson, H. M. The large srh family of chemoreceptor genes in Caenorhabditis nematodes reveals processes of genome evolution involving large duplications and deletions and intron gains and losses. Genome Res. 10, 192-203 (2000)
65. Graveley, B. R. Alternative splicing: increasing diversity in the proteomic world. Trends Genet. 17, 100-107 (2001)

66. Wolfe, K. H. \& Shields, D. C. Molecular evidence for an ancient duplication of the entire yeast genome. Nature 387, 708-713 (1997)

67. Bowman, S. et al. The complete nucleotide sequence of chromosome 3 of Plasmodium falciparum. Nature 400, 532-538 (1999).

68. Altschul, S. F. et al. Gapped BLAST and PSI-BLAST: a new generation of protein database search programs. Nucleic Acids Res. 25, 3389-3402 (1997).

69. Rubin, G. M. et al. Comparative genomics of the eukaryotes. Science 287, 2204-2215 (2000).

70. Apweiler, R. et al. The InterPro database, an integrated documentation resource for protein families, domains and functional sites. Nucleic Acids Res. 29, 37-40 (2001).

71. Chervitz, S. A. et al. Comparison of the complete protein sets of worm and yeast: orthology and divergence. Science 282, 2022-2028 (1998).

72. Hunt, C. et al. Subtelomeric sequence from the right arm of Schizosaccharomyces pombe chromosome I contains seven permease genes. Yeast 18, 355-361 (2001).

73. Kabsch, W. \& Holmes, K. C. The actin fold. FASEB J. 9, 167-174 (1995).

74. Itoh, T., Matsuda, H. \& Mori, H. Phylogenetic analysis of the third hsp70 homolog in Escherichia coli; a novel member of the Hsc66 subfamily and its possible co-chaperone. DNA Res. 6, 299-305 (1999).

75. Erickson, H. P. Atomic structures of tubulin and FtsZ. Trends Cell Biol. 8, 133-137 (1998).

76. Fisher, D. L. \& Nurse, P. A single fission yeast mitotic cyclin B p34 ${ }^{\mathrm{cd} 2}$ kinase promotes both S-phase and mitosis in the absence of G1 cyclins. EMBO J. 15, 850-860 (1996).

77. Lopez-Girona, A., Furnari, B., Mondesert, O. \& Russell, P. Nuclear localization of Cdc25 is regulated by DNA damage and a 14-3-3 protein. Nature 397, 172-175 (1999).

78. Lundin, L. G. Gene duplications in early metazoan evolution. Semin. Cell Dev. Biol. 10, 523-530 (1999).

\section{Acknowledgements}

We thank the European Commission, the Wellcome Trust and Cancer Research UK for financial support. We also thank all the many people in the fission yeast community for their comments and suggestions at all stages of this project, particularly M. Mitchison and U. Leupold, the founders of fission yeast studies. Cancer Research UK, London Research Institute, comprises Lincoln's Inn Fields and Clare Hall Laboratories of the former Imperial Cancer Research Fund following the merger of the ICRF with the Cancer Research Campaign in February 2002.

\section{Competing interests statement}

The authors declare that they have no competing financial interests.

Correspondence and requests for materials should be addressed to M.A.R. (e-mail: mar@sanger.ac.uk). 
abolish ability of human eRF1 to trigger peptidyl-tRNA hydrolysis. RNA 5, 1014-1020 (1999).

4. Zavialov, A. V., Mora, L., Buckingham, R. H. \& Ehrenberg, M. Release of peptide promoted by the GGQ-motif of class 1 release factors regulates the GTPase activity of RF3. Mol. Cell (in the press).

Song, H. et al. The crystal structure of human eukaryotic release factor eRF1-mechanism of stop codon recognition and peptidyl-tRNA hydrolysis. Cell 100, 311-321 (2000).

6. Vestergaard, B. et al. Bacterial polypeptide release factor RF2 is structurally distinct from eukaryotic eRF1. Mol. Cell 8, 1375-1382 (2001).

. Freistroffer, D. V., Pavlov, M. Y., MacDougall, J., Buckingham, R. H. \& Ehrenberg, M. Release factor RF3 in $E$. coli accelerates the dissociation of release factors RF1 and RF2 from the ribosome in a GTP dependent manner. EMBO J. 16, 4126-4133 (1997).

8. Zavialov, A. V., Buckingham, R. H. \& Ehrenberg, M. A Posttermination ribosomal complex is the guanine nucleotide exchange factor for peptide release factor RF3. Cell 107, 115-124 (2001).

9. van Heel, M. et al. Single-particle electron cryo-microscopy: towards atomic resolution. Q. Rev. Biophys. 33, 307-369 (2000)

10. Yusupov, M. M. et al. Crystal structure of the ribosome at 5.5 A resolution. Science 292, 883-896 (2001).

11. Moffat, J. G. \& Tate, W. P. A single proteolytic cleavage in release factor 2 stabilizes ribosome binding and abolishes peptidyl-tRNA hydrolysis activity. J. Biol. Chem. 269, 18899-18903 (1994).

12. Tin, O. F. et al. Proteolytic fragmentation of polypeptide release factor 1 of Thermus thermophilus and crystallization of the stable fragments. Biochimie 82, 765-772 (2000).

13. Kastner, B., Trotman, C. N. \& Tate, W. P. Localization of the release factor-2 binding site on $70 \mathrm{~S}$ ribosomes by immuno-electron microscopy. J. Mol. Biol. 212, 241-245 (1990).

14. Wilson, K. S., Ito, K., Noller, H. F. \& Nakamura, Y. Functional sites of interaction between release factor RF1 and the ribosome. Nature Struct. Biol. 7, 866-870 (2000).

15. Xu, W., Pagel, F. T. \& Murgola, E. J. Mutations in the GTPase center of Escherichia coli $23 \mathrm{~S}$ rRNA indicate release factor 2-interactive sites. J. Bacteriol. 184, 1200-1203 (2002).

16. Wimberly, B. T., Guymon, R., McCutcheon, J. P., White, S. W. \& Ramakrishnan, V. A detailed view of a ribosomal active site: the structure of the L11-RNA complex. Cell 97, 491-502 (1999).

17. Conn, G. L., Draper, D. E., Lattman, E. E. \& Gittis, A. G. Crystal structure of a conserved ribosomal protein-RNA complex. Science 284, 1171-1174 (1999).

18. Yusupova, G. Z., Yusupov, M. M., Cate, J. H. \& Noller, H. F. The path of messenger RNA through the ribosome. Cell 106, 233-241 (2001).

19. Uno, M., Ito, K. \& Nakamura, Y. Polypeptide release at sense and noncognate stop codons by localized charge-exchange alterations in translational release factors. Proc. Natl Acad. Sci. USA 99, 1819-1824 (2002).

20. Nissen, P. et al. Crystal structure of the ternary complex of Phe-tRNAPhe, EF-Tu, and a GTP analog. Science 270, 1464-1472 (1995)

21. Ito, K., Ebihara, K., Uno, M. \& Nakamura, Y. Conserved motifs in prokaryotic and eukaryotic polypeptide release factors: tRNA-protein mimicry hypothesis. Proc. Natl Acad. Sci. USA 93, 5443-5448 (1996).

22. Bertram, G., Bell, H. A., Ritchie, D. W., Fullerton, G. \& Stansfield, I. Terminating eukaryote translation: domain 1 of release factor eRF1 functions in stop codon recognition. RNA 6, 1236-1247 (2000).

23. Frolova, L. Y., Seit-Nebi, A. \& Kisselev, L. L. Highly conserved NIKS tetrapeptide is functionally essential in eukaryotic translation termination factor eRF1. RNA 8, 129-136 (2002).

24. Inagaki, Y., Blouin, C., Doolittle, W. F. \& Roger, A. J. Convergence and constraint in eukaryotic release factor 1 (eRF1) domain 1: the evolution of stop codon specificity. Nucleic Acids Res. 30, 532-544 (2002).

25. Merkulova, T. I., Frolova, L. Y., Lazar, M., Camonis, J. \& Kisselev, L. L. C-terminal domains of human translation termination factors $\mathrm{eRF} 1$ and $\mathrm{eRF} 3$ mediate their in vivo interaction. FEBS Lett. 443, 41-47 (1999).

26. Jelenc, P. C. \& Kurland, C. G. Nucleotide triphosphate regeneration decreases the frequency of translation errors. Proc. Natl Acad. Sci. USA 76, 3174-3178 (1979).

27. Harauz, G. \& van Heel, M. Exact filters for general geometry three-dimensional reconstruction. Optik 73, 146-156 (1986).

28. Jones, T. A., Zou, J. Y., Cowan, S. W. \& Kjeldgaard, M. Improved methods for building protein models in electron density maps and the location of errors in these models. Acta Crystallogr. A 47, 110-119 (1991).

29. Evans, S. V. Setor: Hardware lighted three-dimensional solid model representations of macromolecules. J. Mol. Graphics 11, 134-138 (1993).

Supplementary Information accompanies the paper on Nature's website

( http://www.nature.com). A stereo representation of figure 3 and the FSC plot to assess the resolution of the reconstruction are provided.

Acknowledgements We thank M. Kjeldgaard for making the RF2 coordinates available before deposition; E. Murgola for sharing data before publication; E. Morris, R. Finn and R. Matadeen for discussions on image processing; M. Schatz and R. Schmidt for improvements to the IMAGIC software system; G. Willoughby for computational support; and R. Brimacombe for discussions. This work was supported in part by grants from the BBSRC and the EU. B.V. was funded by the NIH. A.V.Z. and M.E. were supported by the Swedish Foundation for Strategic Research and the Swedish Research Council.

Competing interests statement The authors declare competing financial interests: details accompany the paper on Nature's website (http://www.nature.com/nature).

Correspondence and requests for materials should be addressed to M.v.H.

(e-mail: m.vanheel@ic.ac.uk). The atomic coordinates of the E. coli RF2 structure fitted into the cryo-EM map have been deposited in the Protein Data Bank (e-mail: http://www.rcsb.org) with the accession code 1ML5. The cryo-EM map has been deposited in the 3D EM data base (e-mail: http://www.ebi.ac.uk/msd/MSDProjects/IIMS3D_EM.html) with the accession code EMD-1005.

\section{corrigenda}

\section{The genome sequence of Schizosaccharomyces pombe}

V. Wood, R. Gwilliam, M.-A. Rajandream, M. Lyne, R. Lyne, A. Stewart, J. Sgouros, N. Peat, J. Hayles, S. Baker, D. Basham, S. Bowman, K. Brooks, D. Brown, S. Brown, T. Chillingworth, C. Churcher, M. Collins, R. Connor, A. Cronin, P. Davis, T. Feltwell, A. Fraser, S. Gentles, A. Goble, N. Hamlin, D. Harris, J. Hidalgo, G. Hodgson, S. Holroyd, T. Hornsby, S. Howarth, E. J. Huckle, S. Hunt, K. Jagels, K. James, L. Jones, M. Jones, S. Leather, S. McDonald, J. McLean, P. Mooney, S. Moule, K. Mungall, L. Murphy, D. Niblett, C. Odell, K. Oliver, S. O'Neil, D. Pearson, M. A. Quail, E. Rabbinowitsch, K. Rutherford, S. Rutter, D. Saunders, K. Seeger, S. Sharp, J. Skelton, M. Simmonds, R. Squares, S. Squares, K. Stevens, K. Taylor, R. G. Taylor, A. Tivey, S. Walsh, T. Warren, S. Whitehead, J. Woodward, G. Volckaert, R. Aert, J. Robben, B. Grymonprez, I. Weltjens, E. Vanstreels, M. Rieger, M. Schäfer, S. Müller-Auer, C. Gabel, M. Fuchs, A. Düsterhöft, C. Fritzc, E. Holzer, D. Moestl, H. Hilbert, K. Borzym, I. Langer, A. Beck, H. Lehrach, R. Reinhardt, T. M. Pohl, P. Eger, W. Zimmermann, H. Wedler, R. Wambutt, B. Purnelle, A. Goffeau, E. Cadieu, S. Dréano, S. Gloux, V. Lelaure, S. Mottier, F. Galibert,

S. J. Aves, Z. Xiang, C. Hunt, K. Moore, S. M. Hurst, M. Lucas, M. Rochet, C. Gaillardin, V. A. Tallada, A. Garzon, G. Thode, R. R. Daga, L. Cruzado, J. Jimenez, M. Sánchez, F. del Rey, J. Benito, A. Dominguez,

J. L. Revuelta, S. Moreno, J. Armstrong, S. L. Forsburg, L. Cerutti, T. Lowe, W. R. McCombie, I. Paulsen, J. Potashkin, G. V. Shpakovski, D. Ussery, B. G. Barrell \& P. Nurse

Nature 415, 871-880 (2002).

In this Article, the author Andreas Düsterhöft was mistakenly omitted: his name and affiliation (footnote 6) should have been inserted between M. Fuchs and C. Fritzc in the author list. In addition, the name of L. Cerutti (in the last line of the author list) was misspelled. On p874 in the penultimate sentence of the 'Intergene regions' section, "tandemly oriented genes" should read "divergently oriented genes."

\section{Probing the free-energy surface for protein folding with single- molecule fluorescence spectroscopy}

\author{
Benjamin Schuler, Everett A. Lipman \& William A. Eaton
}

Nature 419, 743-747 (2002).

The upper limit on the polypeptide reconfiguration time $\left(\tau_{0}\right)$ was inadvertently calculated using $\left(\sigma_{\mathrm{app}}-\sigma_{0}\right)^{2}$, instead of $\left(\sigma_{\mathrm{app}}^{2}-\sigma_{0}^{2}\right)$, as given in the formula in the text (page 745 , right column). The correct upper limit is therefore $0.2 \mathrm{~ms}$. This results in a lower limit on the free energy barrier $(\Delta)$ of $2 k_{\mathrm{B}} T$, corresponding to an activation entropy of $+3 k_{\mathrm{B}}$ (page 746 , right column), and an upper limit on the pre-exponential factor $\left(2 \pi \tau_{0}\right)$ of $1 \mathrm{~ms}$. This mistake does not affect any of the conclusions. We thank Taekjip Ha for bringing it to our attention. 